Purdue University

Purdue e-Pubs

CTRC Research Publications

Cooling Technologies Research Center

2014

\title{
Local Single- and Two-Phase Heat Transfer from an Impinging Cross-Shaped Jet
}

M.J. Rau

Purdue University

E. M. Dede

Toyota Research Institute

S V. Garimella

Purdue University, sureshg@purdue.edu

Follow this and additional works at: http://docs.lib.purdue.edu/coolingpubs

Rau, M. J.; Dede, E. M.; and Garimella, S V., "Local Single- and Two-Phase Heat Transfer from an Impinging Cross-Shaped Jet" (2014). CTRC Research Publications. Paper 236.

http://dx.doi.org/http://dx.doi.org/10.1016/j.ijheatmasstransfer.2014.08.012

This document has been made available through Purdue e-Pubs, a service of the Purdue University Libraries. Please contact epubs@purdue.edu for additional information. 


\title{
Local single- and two-phase heat transfer from an impinging cross- shaped jet ${ }^{1}$
}

\author{
Matthew J. Rau*, Ercan M. Dede ${ }^{\dagger}$, Suresh V. Garimella*2 \\ *School of Mechanical Engineering \\ Purdue University, 585 Purdue Mall, West Lafayette, IN 47907 USA \\ ${ }^{\dagger}$ Electronics Research Department \\ Toyota Research Institute of North America, 1555 Woodridge Ave., Ann Arbor, MI 48105 USA
}

\begin{abstract}
Local single- and two-phase heat transfer distributions are measured under a confined impinging jet issuing from a cross-shaped orifice. Spatially resolved temperature maps and convection coefficients resulting from the impinging flow are obtained via infrared imaging of a thin-foil heat source. The cooling patterns in single- and two-phase operation are explained by an accompanying numerical investigation of the fluid flow issuing from the orifice; computed velocity magnitudes and turbulence intensities are presented. In single-phase operation, the coolest surface temperatures correspond to areas with high liquid velocities. High velocities and developing turbulence are also shown to increase convective heat transfer along the diagonal outflow directions from the impinging jet. During two-phase transport, boiling preferentially begins in regions of low velocity, providing enhanced heat transfer in the areas least affected by the impingement. The cross-shaped orifice achieves local heat transfer coefficients that exceed the stagnation-point value of a circular jet of equivalent open orifice area by up to 1.5 times, while resulting in an increased pressure drop only 1.1 times higher than that of the circular jet.
\end{abstract}

\footnotetext{
${ }^{1}$ Submitted for possible publication in International Journal of Heat and Mass Transfer, June 2014

${ }^{2}$ Corresponding author, Tel: +1 765494 5621. E-mail address: sureshg@purdue.edu.
} 


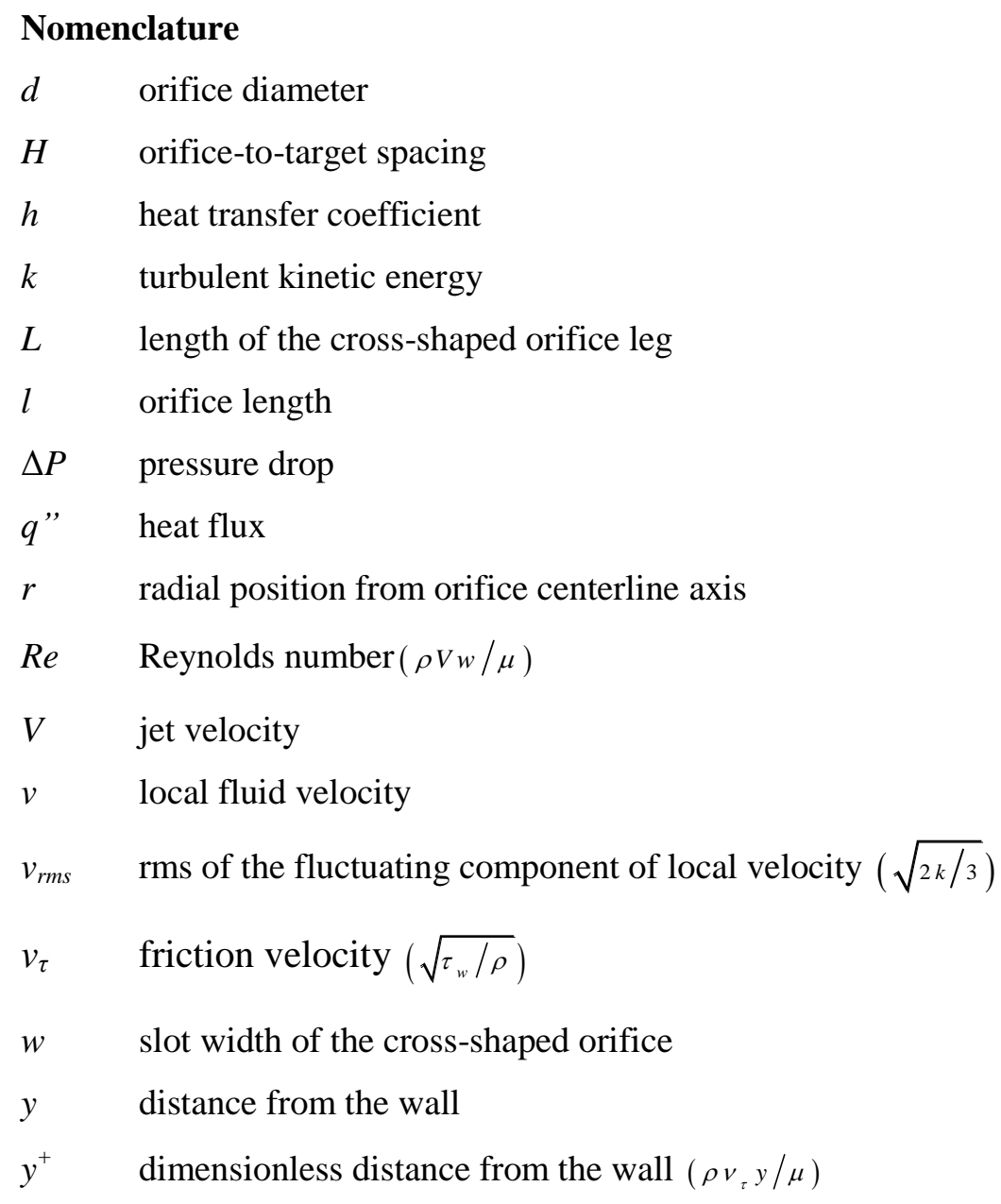

\section{Greek symbols}

$\mu \quad$ dynamic viscosity

$\rho$ density

$\tau_{w} \quad$ wall shear stress

\section{Keywords}

Jet impingement, cross-shaped jet, two-phase cooling, boiling, HFE-7100, infrared thermography

\section{Introduction}

Two-phase jet impingement combines high convective heat transfer rates with enhanced heat dissipation from boiling. Altering the shape of the orifice can influence local fluid velocities and turbulence levels in a manner that affects local heat transfer distributions; the unique flow fields resulting 
from different orifice geometries may require different placement of enhancement structures on the target surface for optimal heat transfer enhancement.

In a recent comparison of orifice geometries in two-phase jet impingement, Rau and Garimella [1] showed that the uniformity of heat transfer from the surface was highly dependent on the orifice configuration. Arrays of circular jets provided higher area-averaged heat transfer coefficients than a single jet of identical open orifice area, but with more non-uniformity in temperature at heat fluxes that induced boiling. Significant increases in the boiling heat transfer coefficient and critical heat flux were achieved with surface enhancement structures [2]; this enhancement was maximized when the placement of surface structures complemented the impinging liquid flow from a $5 \times 5$ array of jets [3].

Novel orifice shapes used in conjunction with surface enhancements were investigated for microsized evaporative spray nozzles [4,5], but have received little attention in the two-phase jet impingement literature. For single-phase confined impinging jets, small jet orifice lengths $(l / d<1)$ resulted in higher heat transfer coefficients compared to longer orifices [6]. Shaping the orifice by chamfering was then found to reduce the pressure drop without significantly affecting the cooling performance of the impinging jets [7]. Non-circular free jets resulted in enhanced turbulent mixing rates when compared to circular jets [8,9]. Gulati et al. [10] investigated air jets formed by circular, square, and rectangular orifices for single-phase impingement cooling. The rectangular orifice resulted in higher heat transfer coefficients in the stagnation region at low jet-to-target spacings, which was attributed to increased turbulence. This slight enhancement was accompanied by an increase in pressure loss coefficient compared to the circular orifice. Nastase et al. [11] showed that focused streamwise vortical structures can develop between the legs (along the diagonal plane) of a free cross-shaped jet. These vortices were found to be the direct cause of the enhanced turbulent mixing and entrainment rates of the cross-shaped jet compared to a circular jet of equivalent orifice area. In a later study of a cross-shaped jet in an impingement configuration [12], these vortices were shown to cause high local mass transfer coefficients on the surface along these diagonal directions.

Before surface enhancements can be tailored for cross-shaped orifices, the flow field and local heat transfer characteristics must be understood. The current study maps the single- and two-phase heat transfer resulting from an impinging jet of HFE-7100 issuing from a cross-shaped orifice. Local temperatures and heat transfer coefficients are obtained with high spatial resolution by use of infrared (IR) thermography. Heat transfer coefficients are compared to those of a circular orifice of equivalent open area at three volumetric flow rates. The unique cooling patterns observed with the cross-shaped orifice are discussed in detail and further explained using a numerical flow field investigation. Experimental and numerical pressure drop results are also reported. 


\section{Experimental setup}

The cross-shaped liquid jet is formed by pumping the degassed dielectric liquid HFE-7100 (3M, $T_{\text {sat }}=$ $61{ }^{\circ} \mathrm{C}$ at atmospheric pressure) through a cross-shaped jet orifice. The jet impinges onto a thin-foil heat source $(50 \mu \mathrm{m}$ thick), backed by an infrared window, for spatial temperature mapping with an infrared camera. The experimental facility and procedures used in the current study are identical to those reported in [1] and additional details on the flow loop, test section, thin-foil heat source, and experimental procedures are omitted here for brevity. The data reduction procedures are also identical to the previous study with one exception being the local pressure correction employed. In [1], the local pressure along the heated surface due to the added impingement pressure of the circular jet was approximated as a bellshaped distribution to calculate local fluid saturation temperatures at the wall. Due to complex flow from the cross-shaped jet orifice in the current study, the wall pressure correction is not applied, and the saturation temperature of the fluid is assumed constant across the $12 \mathrm{~mm} \times 12 \mathrm{~mm}$ heated area over which measurements in this work are presented.

The cross-shaped jet orifice used for the current investigation is shown in Figure 1a along with the circular orifice ( $d=3.75 \mathrm{~mm}$ ) from [1]. To allow comparison, the width $w$ and length $L$ of the cross legs are chosen such that the total open area of the cross-shaped orifice is equal to that of the circular orifice. The cross-shaped orifice is positioned at a height $H$ of $2.96 \mathrm{~mm}(H / w=4)$ for consistency with the nondimensional spacing used for the circular jet $(H / d=4)$. The length of the orifice $l$ (i.e. the thickness of the orifice plate) is twice the width of one leg $(l / w=2)$. The experiments are conducted at flow rates of 450,900 , and $1800 \mathrm{ml} / \mathrm{min}$, resulting in Reynolds numbers based on the leg width $(w)$ of 1850,3700 , and 7700.

\section{Numerical model}

A one-quarter symmetry geometry including the inlet manifold, jet orifice, and confined outflow region is used to represent the experimental test section as shown in Figure 1b. Due to the turbulent nature of the flow, a Reynolds-averaged Navier-Stokes (RANS) Shear Stress Transport (SST) turbulence model is chosen in a commercial software environment [13]. The SST turbulence model is a hybrid model that is adopted with the goal of improving the prediction of turbulence in adverse pressure gradients; it combines the benefits of a $k-\omega$ model near the wall with the strengths of a $k-\varepsilon$ model farther from the wall [14].

A fixed normal velocity condition corresponding to the experimentally studied flow rate is enforced at the inlet boundary of the model. A fixed pressure boundary condition is assumed at the outlet. Appropriate flow symmetry boundary conditions are applied to the geometry, as shown in Figure 1b. Thermophysical material parameters for HFE-7100 are calculated based on the average film temperature 
for each case. For the $450 \mathrm{ml} / \mathrm{min}$ results presented, a fixed fluid density and dynamic viscosity of 1395 $\mathrm{kg} / \mathrm{m}^{3}$ and $3.53 \times 10^{-4} \mathrm{~Pa}$-s, respectively, are used. The SST model requires a finely spaced computational mesh near the wall to ensure accuracy. A refinement study was performed to arrive upon the final grid comprising $3.26 \times 10^{5}$ elements, which includes: approximately 30 elements across the orifice leg width, 10 elements across boundary layers at all walls with a minimum size of $0.01 \mathrm{~mm}$ for accuracy, and a $y^{+}$value generally less than 2 for precise flow separation prediction.

\section{Heat transfer and flow field results}

A temperature map obtained from the cross-shaped jet in single-phase operation (prior to any vapor generation at the surface) at a heat flux of $2.8 \mathrm{~W} / \mathrm{cm}^{2}$ and a flow rate of $450 \mathrm{ml} / \mathrm{min}$ is shown in Figure 2a. The dashed outline of the orifice is also shown in the figure. The lowest temperatures do not occur at the center of the cross, but instead close to the outer tips of each leg, indicating that the impingement heat transfer coefficients are highest at these locations. The diagonal directions of the heat source (centerline of the orifice to the corners of the temperature map) also display relatively cool temperatures that are sustained well outside the region beneath the orifice, indicating that radial outflow from the cross-shaped jet is dominant along these diagonals. Velocity magnitudes obtained from the numerical investigation at the same volumetric flow rate (shown in Figure 3a) confirm this conclusion. The impinging flow from the cross-shaped jet creates preferential outflow paths along the diagonals issuing from the centerline of the orifice, resulting in high velocities along these directions. In the plane-cut shown in Figure $3 \mathrm{a}$, the velocities along the diagonals are almost 6 times higher than those directly downstream of the tips of the orifice legs. For example at $x=4 \mathrm{~mm}$ and $y=4 \mathrm{~mm}$, the local liquid velocity is $v=0.62 \mathrm{~m} / \mathrm{s}$, whereas at $x=4 \mathrm{~mm}$ and $y=0 \mathrm{~mm}$, the local velocity is only $v=0.11 \mathrm{~m} / \mathrm{s}$.

The surface temperatures at a heat flux of $10.0 \mathrm{~W} / \mathrm{cm}^{2}$ are shown in Figure 2b, and display smallscale spatial temperature variations in areas surrounding the impingement region of the cross-shaped jet caused by boiling at these locations. The isolated cool regions at the tips of each orifice leg are still discernable in the temperature map. By comparing the temperature map in Figure $2 b$ to the velocity contour plot in Figure 3a, it is observed that boiling seems to be most prevalent in the areas corresponding to low single-phase liquid velocities on the heated surface.

Local heat transfer coefficient profiles on the heat source are plotted along the lateral (Figure 4a) and diagonal (Figure 4b) directions for a range of heat fluxes at each flow rate. The lowest curve in each plot represents the lowest specified heat flux and presents a single-phase case where no vapor bubble formation is observed. The single-phase heat transfer coefficient profile obtained for the circular jet of [1] is also plotted. The profiles show that the circular jet maintains a higher heat transfer coefficient at the center of the impinging jet $(r=0 \mathrm{~mm})$; however, the cross-shaped orifice results in local heat transfer 
coefficients that exceed the stagnation point values of the circular jet, shown plotted in the lateral direction in Figure $4 \mathrm{a}(r=2.9 \mathrm{~mm})$. This local maximum in heat transfer coefficient is caused by the high impingement velocity from the orifice at this location, which is evident in the velocity contour plot shown in Figure 3a. Along the diagonal direction, a local minimum in heat transfer coefficient occurs at this same distance from the centerline of the orifice $(r=2.9 \mathrm{~mm})$, after which $h$ steadily increases downstream. The increase in heat transfer coefficient is due to the development of turbulence along the high-velocity diagonal outflow paths, shown in Figure $3 \mathrm{~b}$ using contours of turbulence intensity obtained from the numerical flow field investigation. As the turbulence intensity increases downstream of the orifice, the local heat transfer coefficient increases. The high velocity and turbulence along these diagonal outflow paths suggest that area-enhancing finned structures might be most beneficial in these regions for enhancing the heat transfer.

Local enhancement caused by boiling is identified as an increase in heat transfer coefficient at a constant flow rate as the heat flux is increased. This enhancement with heat flux is observed in Figure 4 predominantly in the locations that correspond to low-velocity regions on the heated surface, most readily seen at the lowest flow rate of $450 \mathrm{ml} / \mathrm{min}$. When considering the placement of surface enhancement structures, nucleation site promoters might be more beneficial than area-enhancements in these lowvelocity regions to promote enhanced boiling heat transfer. As in [1], the upper heat flux imposed in each test is limited to the value at which film boiling is observed to occur at the heater edges (outside the infrared camera view). At the heat fluxes shown, boiling does not propagate inward to the central impingement region of the jet; single-phase convection is the dominant heat transfer mechanism in this region. At the higher flow rates investigated, little to no boiling occurs, as indicated by the profiles at 900 and $1800 \mathrm{ml} / \mathrm{min}$ in Figure 4.

Figure 5 plots the pressure drop for the cross-shaped orifice at the three jet velocities investigated. Experimentally measured values, as well as those obtained numerically, are included and compared to values for the circular orifice from [1]. The pressure drop for the cross-shaped orifice is found to be independent of the heat flux applied and any vapor generation due to boiling, and therefore only the single-phase value is plotted in Figure 5. The cross-shaped orifice results in a slightly higher pressure drop than the circular orifice, a result consistent with [10], where rectangular jet orifices were shown to have a higher pressure loss coefficient than a circular jet orifice. The pressure drop calculated from the numerical model (average pressure at the inlet minus the pressure at the outlet of the domain) shows good agreement with the experimental results (with a mean error of $8.7 \%$, reinforcing the robustness of the numerical scheme used for the investigation).

\section{Conclusions}


Local temperatures and heat transfer coefficients obtained for an impinging jet formed by a crossshaped orifice are presented. The resulting flow field obtained from a numerical model of the turbulent liquid flow is used to understand the observed heat transfer distribution over the surface. Heat transfer and pressure drop results are compared to those from a circular jet orifice of equivalent open orifice area at volumetric flow rates of 450,900 , and $1800 \mathrm{ml} / \mathrm{min}$.

The cross-shaped jet is shown to result in a slightly higher pressure drop compared to the circular orifice. The cross shape greatly influences the local liquid velocities and turbulence on the heated surface; the single-phase heat transfer along the diagonal outflow paths increases with increasing turbulence intensity in these high-velocity regions. The cross-shaped jet also results in local heat transfer coefficients that exceed the stagnation point value of the circular jet. In two-phase operation, enhancement from boiling heat transfer is shown to occur predominantly in regions of low liquid velocities identified in the accompanying simulations. The results obtained here for the cross-shaped orifice suggest the use of standard surface-area enhancements in regions dominated by single-phase heat transfer in combination with nucleation-site enhancements in areas of low liquid velocities for enhanced two-phase operation.

\section{Acknowledgements}

The authors thank Toyota Motor Engineering and Manufacturing North America, Inc. for their support of this work. 


\section{References}

1 M.J. Rau, S.V. Garimella, Local two-phase heat transfer from arrays of confined and submerged impinging jets, Int. J. Heat Mass Tran. 67 (2013) 487-498.

2 M.J. Rau, S.V. Garimella, Confined jet impingement with boiling on a variety of enhanced surfaces, J. Heat Transf. (in review).

3 M.J. Rau, S.V. Garimella, E.M. Dede, S.N. Joshi, Boiling heat transfer from an array of round jets with hybrid surface enhancements, J. Heat Transf. (in review).

4 C.H. Amon, J. Murthy, S.C. Yao, S. Narumanchi, C.-F. Wu, C.-C. Hsieh, MEMS-enabled thermal management of high-heat-flux devices EDIFICE: embedded droplet impingement for integrated cooling of electronics, Exp. Therm. Fluid Sci. 25 (2001) 231-242.

5 C.H. Amon, S.-C. Yao, C.-F. Wu, C.-C. Hsieh, Microelectromechanical system-based evaporative thermal management of high heat flux electronics, J. Heat Transf. 127 (2005) 66-75.

6 S.V. Garimella, B. Nenaydykh, Nozzle-geometry effects in liquid jet impingement heat transfer, Int. J. Heat Mass Tran. 39(14) (1996) 2915-2923.

7 L.A. Brignoni, S.V. Garimella, Effects of nozzle-inlet chamfering on pressure drop and heat transfer in confined air jet impingement, Int. J. Heat Mass Tran. 43 (2000) 1133-1139.

8 D.S. Liscinsky, B. True, J.D. Holdeman, Crossflow mixing of noncircular jets, J. Propul. Power 12(2) (1996) 225-230.

9 J. Mi, G.J. Nathan, R.E. Luxton, Centreline mixing characteristics of jets from nine differently shaped nozzles, Exp. Fluids 28 (2000) 93-94

10 P. Gulati, V. Katti, S.V. Prabhu, Influence of the shape of the nozzle on local heat transfer distribution between smooth flat surface and impinging air jet, Int. J. Therm. Sci. 48 (2009) 602-617.

11 I. Nastase, A. Meslem, P. Gervais, Primary and secondary vortical structures contribution in the entrainment of low Reynolds number jet flows, Exp. Fluids 44 (2008) 1027-1033.

12 M. Kristiawan, A. Meslem, I. Nastase, V. Sobolik, Wall shear rates and mass transfer in impinging jets: Comparison of circular convergent and cross-shaped orifice nozzles, Int. J. Heat Mass Tran. 55 (2012) 282-293.

13 COMSOL AB, COMSOL Multiphysics Ver. 4.3b (2013). Stockholm.

14 N. Zuckerman, N. Lior, Jet impingement heat transfer: physics, correlations, and numerical modeling, Adv. Heat Transf. 39 (2006) 565-631. 


\section{List of Figures}

Figure 1. (a) Cross-shaped orifice overlaid on top of an outline of the $12 \mathrm{~mm} \times 12 \mathrm{~mm}$ heat source (circular orifice from [1] shown for comparison), and (b) the fluid domain and boundary conditions used for the numerical flow field investigation.

Figure 2. Experimentally obtained temperature maps of the heated surface cooled by the cross-shaped jet at a flow rate of $450 \mathrm{ml} / \mathrm{min}$ in (a) single-phase $(\mathrm{q} "=2.8 \mathrm{~W} / \mathrm{cm} 2)$, and (b) two-phase $(\mathrm{q} "=10.0 \mathrm{~W} / \mathrm{cm} 2)$ operation. An overlay of the cross-shaped orifice is shown with dashed lines.

Figure 3. Numerical model results showing (a) velocity contours and, (b) turbulence intensities normalized with the jet velocity visualized on a plane cut positioned $1 \mathrm{~mm}$ above the heated surface. Figure 4. Heat transfer coefficient profiles plotted along (a) the lateral, and (b) the diagonal directions over a range of heat fluxes, at the three volumetric flow rates considered. The single-phase heat transfer coefficient profile for the circular jet from [1] is also shown as a dashed line for comparison.

Figure 5. Experimental and numerical pressure drop values obtained for the cross-shaped orifice as a function of jet velocity $(V)$. Experimental pressure drop values obtained for the circular orifice in [1] are shown for comparison. 


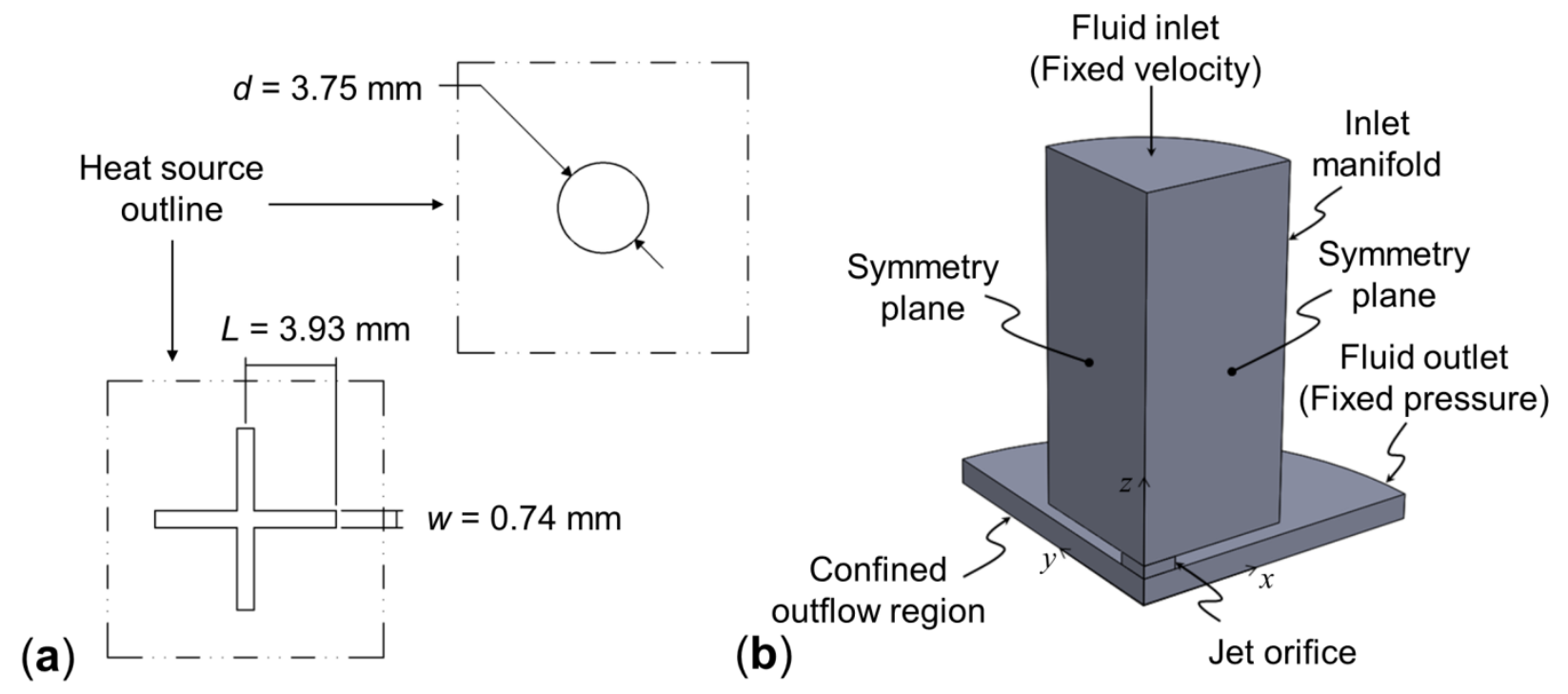

Figure 1. (a) Cross-shaped orifice overlaid on top of an outline of the $12 \mathrm{~mm} \times 12 \mathrm{~mm}$ heat source (circular orifice from [1] shown for comparison), and (b) the fluid domain and boundary conditions used for the numerical flow field investigation. 

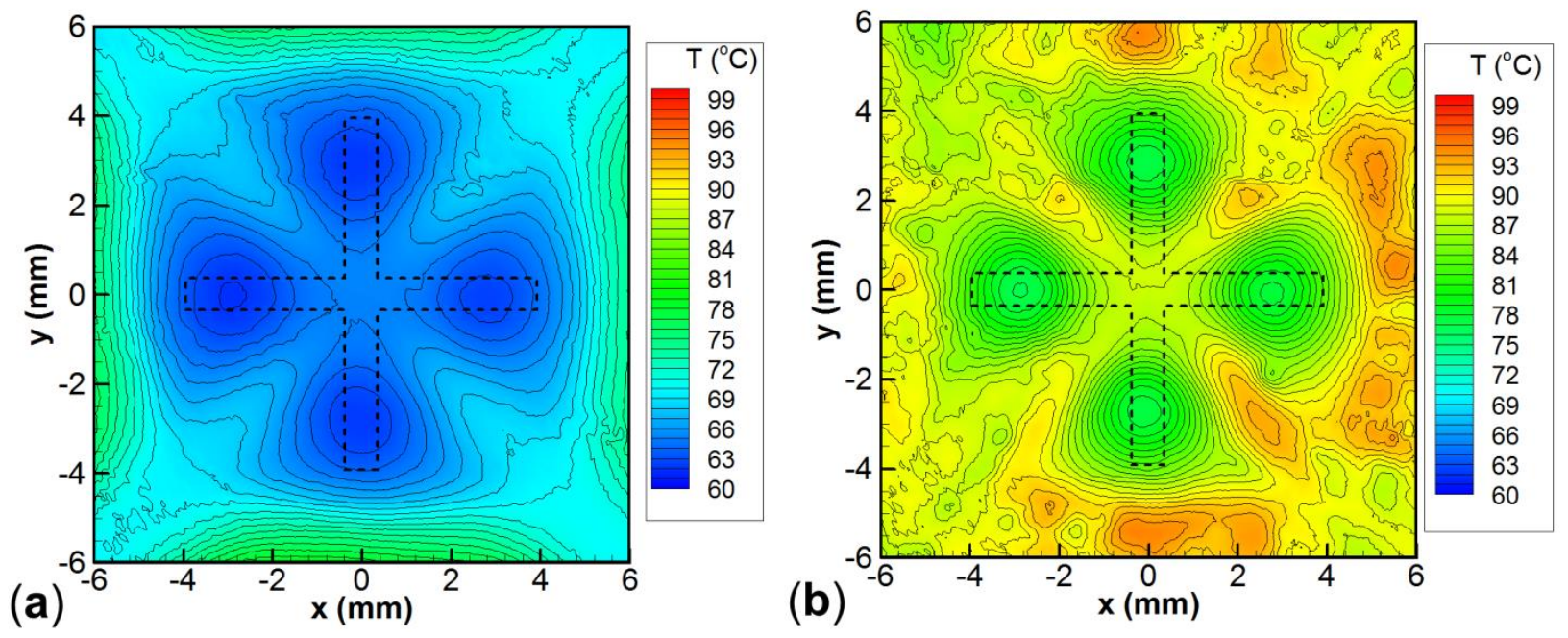

Figure 2. Experimentally obtained temperature maps of the heated surface cooled by the cross-shaped jet at a flow rate of $450 \mathrm{ml} / \mathrm{min}$ in (a) single-phase $\left(q "=2.8 \mathrm{~W} / \mathrm{cm}^{2}\right)$, and (b) two-phase $\left(q "=10.0 \mathrm{~W} / \mathrm{cm}^{2}\right)$ operation. An overlay of the cross-shaped orifice is shown with dashed lines. 

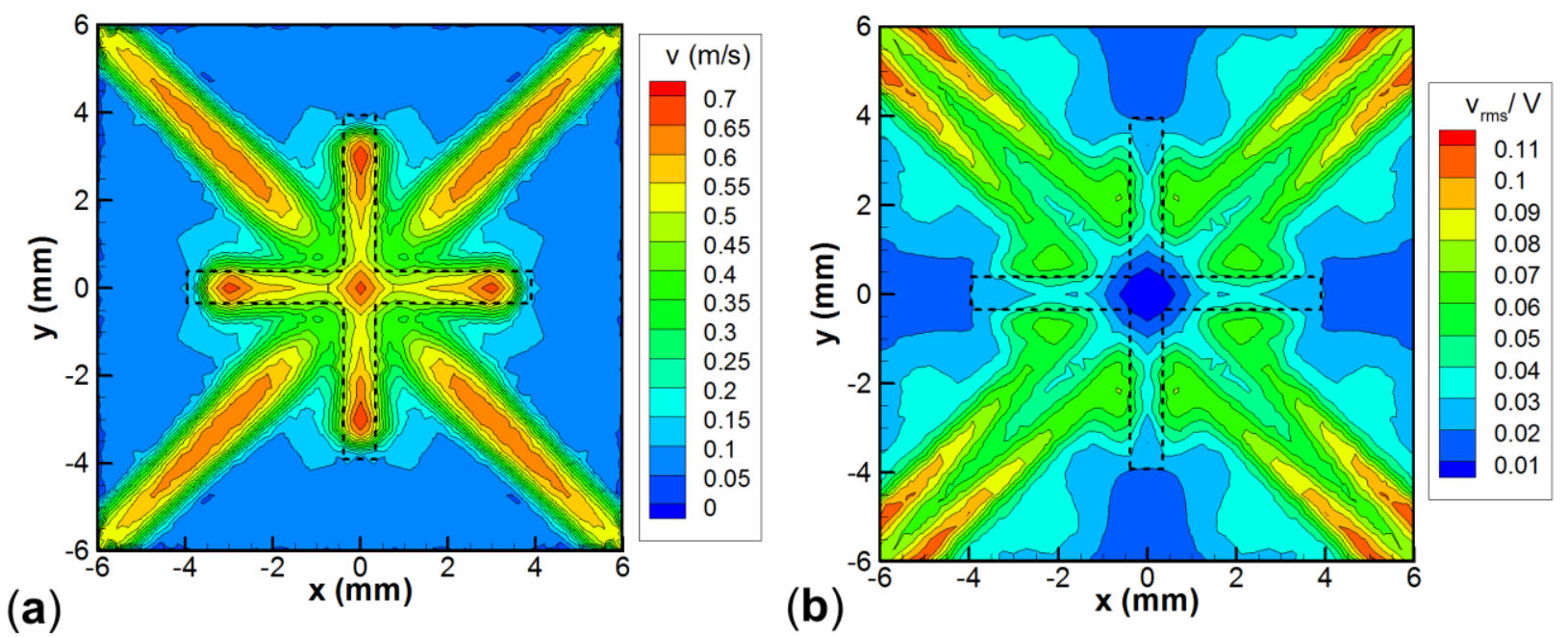

Figure 3. Numerical model results showing (a) velocity contours and, (b) turbulence intensities normalized with the jet velocity visualized on a plane cut positioned $1 \mathrm{~mm}$ above the heated surface. Results are plotted for a flow rate of $450 \mathrm{ml} / \mathrm{min}$. An overlay of the cross-shaped orifice is shown with dashed lines. 



Figure 4. Heat transfer coefficient profiles plotted along (a) the lateral, and (b) the diagonal directions over a range of heat fluxes, at the three volumetric flow rates considered. The single-phase heat transfer coefficient profile for the circular jet from [1] is also shown as a dashed line for comparison. 




Figure 5. Experimental and numerical pressure drop values obtained for the cross-shaped orifice as a function of jet velocity $(V)$. Experimental pressure drop values obtained for the circular orifice in [1] are shown for comparison. 